\title{
Fatigue Behavior of Multi-Directionally Forged Commercial Purity Grade 2 Ti Plate in Laboratory Air and Ringer's Solution
}

\author{
Ilhamdi $^{1,2}$, Toshifumi Kakiuchi ${ }^{3}$, Hiromi Miura ${ }^{4}$, Tomohiko Fukihara ${ }^{5}$ and Yoshihiko Uematsu ${ }^{2, *}$ \\ ${ }^{1}$ Graduate School of Engineering, Gifu University, Gifu 501-1193, Japan \\ ${ }^{2}$ Andalas University, Limau Manis, Pauh, Kota Padang, Sumatera Barat 25163, Indonesia \\ ${ }^{3}$ Department of Mechanical Engineering, Gifu University, Gifu 501-1193, Japan \\ ${ }^{4}$ Department of Mechanical Engineering, Toyohashi University of Technology, Toyohashi 441-8580, Japan \\ ${ }^{5}$ NGK Spark Plug Co., Ltd., Nagoya 467-8525, Japan
}

Ultrafine-grained pure titanium (Ti) plates with the thickness of $1 \mathrm{~mm}$ were fabricated by a combined process of multi-directional forging (MDFing) and cold rolling (here after referred as MDFed pure Ti for simplicity) aiming at the dental implant application. The plates exhibited higher tensile strength than the conventional cold-rolled pure Ti plates due to the ultrafine-grained structure with an average size of $200 \mathrm{~nm}$. The axial fatigue tests were conducted in laboratory air and in Ringer's solution to investigate long-term durability as dental implants. The fatigue strengths of the MDFed pure Ti plates in laboratory air were higher than those of the cold-rolled pure Ti plates as well as the tensile properties. In the high cycle fatigue (HCF) regime, sub-surface crack initiation with fish-eye fracture surface was observed in the MDFed pure Ti plates, while surface crack initiation was dominant in the cold-rolled pure Ti plates. Sub-surface crack generally initiated at the mid-thickness of the thin plates. Inclusions were not recognized at the crack initiation sites, while microstructural analyses revealed that some coarse grains with the size of a few $\mu \mathrm{m}$ distributed around the crack initiation sites. Consequently, the sub-surface crack initiation mechanism was attributed to the inhomogeneity of the microstructure near the mid-thickness of the plates. The corrosion fatigue strengths in Ringer's solution were comparable to those in laboratory air, where sub-surface crack initiation occurred in the HCF regime even in corrosive environment. That indicates the high corrosion resistance of the MDFed pure Ti plates. [doi:10.2320/matertrans.M2018075]

(Received February 28, 2018; Accepted May 9, 2018; Published June 8, 2018)

Keywords: fatigue, corrosion fatigue, pure Ti, multi-directional forging, ultrafine grain, Ringer's solution

\section{Introduction}

Pure titanium (Ti) and $\mathrm{Ti}$ alloys are attractive metallic materials for biomedical application. Especially, Ti-6Al-4V has been widely used as structural materials not only for mechanical components but also for bio implants due to its high strengths and superior corrosion resistances. ${ }^{1-4)}$ The high strengths of $\mathrm{Ti}-6 \mathrm{Al}-4 \mathrm{~V}$ could be attributed to the alloying elements such as aluminum and vanadium to form complicated two-phase microstructure. However, from the viewpoint of long-term use in human body, the alloy additives sometimes could be toxic known as metal allergy. ${ }^{5)}$ Therefore, pure $\mathrm{Ti}$ without any alloying elements is better than Ti-6Al-4V for long-term use as implants, while the strengths of pure $\mathrm{Ti}$ are generally inferior to those of Ti-6Al-4V.

Fleck and Eifler revealed that the fatigue strengths of commercial purity grade $2 \mathrm{Ti}$ were about a quarter of those of Ti-6Al-4V. ${ }^{3)}$ Consequently, the enhancement of the strengths of pure Ti became important issue for the application of medical implants. Recently, sever plastic deformations $\left.(\mathrm{SPD})^{6}\right)$ such as equal channel angular pressing (ECAP), ${ }^{7-11)}$ high pressure torsion (HPT), ${ }^{12}$ accumulative roll-bonding $(\mathrm{ARB})^{13)}$ and so on attract attention as strengthening methods of metals without changing chemical compositions. The SPD methods were developing for wide range of alloys and pure metals such as copper, ${ }^{11)}$ magnesium, ${ }^{12)}$ aluminum, ${ }^{13)}$ titanium $^{7,8)}$ and steels..$^{9,10)}$ The strengthening mechanism is basically attributed to ultrafine-grained (UFGed) microstructures induced by the SPDs. Multi-directional forging (MDFing) process is one of the SPD methods, in which materials are forged with changing forging axes for 90 degrees

*Corresponding author, E-mail: yuematsu@gifu-u.ac.jp pass by pass. ${ }^{14-18)}$ The major advantage of MDFing is that lather large components could be fabricated. Miura et al. developed high strength magnesium alloy, AZ61Mg, by MDFing, and microstructural observation proved that the UFGed microstructure with the average grain size of $200 \mathrm{~nm}$ resulted in the high tensile strength without reducing ductility. ${ }^{14,15)}$ Recently, high strength pure Ti plates were successfully fabricated by combined processes of MDFing and rolling (here after, all they will be referred as MDFed pure Ti for simplicity ${ }^{19)}$ ) aiming at the dental-implant application. This material was developed in collaboration with dentistry researchers, and trial dental crowns were successfully fabricated..$^{20,21)}$ For the long-term durability of implants, it is important to understand high cycle fatigue (HCF) properties of MDFed pure Ti. Furthermore, the evaluation of fatigue strengths in corrosive environment is also important for the implant application. However, the fatigue behavior of MDFed pure $\mathrm{Ti}$ in air and in corrosive environment is not studied. In the present paper, axial load fatigue tests were conducted using MDFed commercial purity grade $2 \mathrm{Ti}$ plates to investigate the fatigue properties. The fatigue test environments are in air and in Ringer's solution to simulate the dental implant application.

\section{Materials and Experimental Procedures}

The material used is MDFed commercial purity grade $2 \mathrm{Ti}$ plate supplied from Kawamoto Heavy Industries, Japan. Because the precise production procedure of the MDFed pure $\mathrm{Ti}$ is not opened, the specimens is simply referred as MDFed pure $\mathrm{Ti}$ as already mentioned above. As shown in Fig. 1, MDFed Ti was received as plates with the length of $750 \mathrm{~mm}$, width of $70 \mathrm{~mm}$ and thickness of $1 \mathrm{~mm}$. The coordinate of 


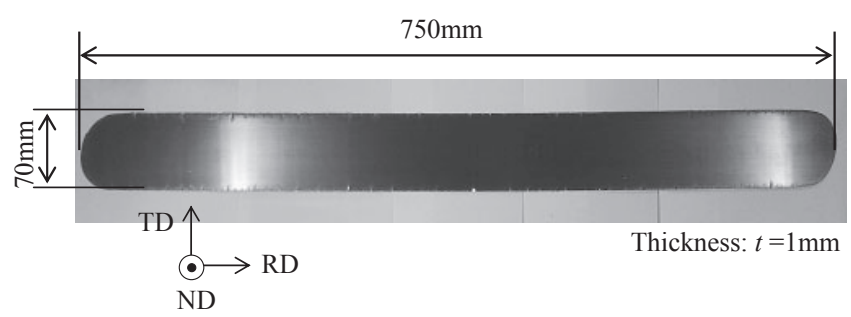

Fig. 1 As-received MDFed Ti plate.

(a)

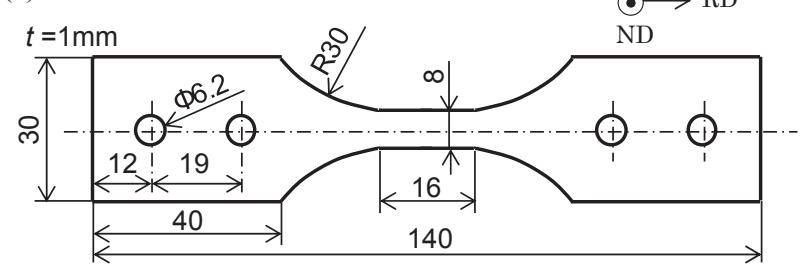

(b)

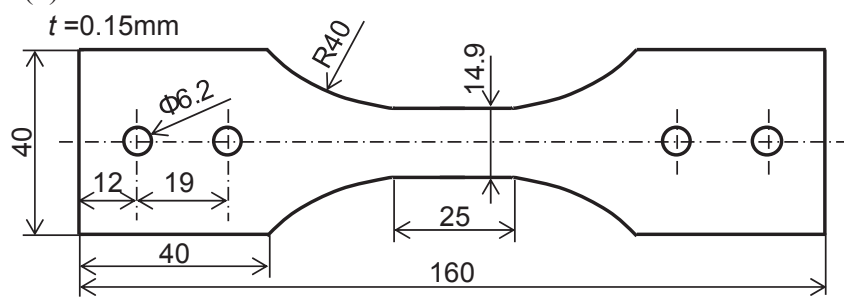

Fig. 2 Specimen configurations: (a) MDFed Ti, (b) TP35C.

rolling direction (RD), transverse direction (TD) and normal direction (ND) is defined as shown in the figure. As a reference material, conventional cold-rolled commercial purity grade $2 \mathrm{Ti}$ was used, which was classified as TP35C in accordance with JIS (Japanese Industrial Standard) H4600. The as-rolled plates have the length of $382 \mathrm{~mm}$, width of $47 \mathrm{~mm}$ and thickness of $0.15 \mathrm{~mm}$.

Fatigue specimens were electrical-discharge machined from the as-received plates and the fatigue specimen configurations for MDFed $\mathrm{Ti}$ and $\mathrm{TP} 35 \mathrm{C}$ are shown in Figs. 2(a) and 2(b), respectively. The fatigue tests were conducted using a $50 \mathrm{kN}$ capacity electro-hydraulic fatigue testing machine. The stress ratio $R=\sigma_{\min } / \sigma_{\max }$ of the fatigue test was set to be 0.1 , namely a tension-tension loading condition. The test frequency was $10 \mathrm{~Hz}$. Before fatigue tests, the edges of the specimens were mechanically polished with progressively finger grades of emery paper, and mirror finished by alumina suspension. Using the MDFed Ti, fatigue tests were conducted in air at ambient temperature and in Ringer's solution at the temperature of $37^{\circ} \mathrm{C}$. The composition of Ringer's solution is $8.6 \mathrm{~g} / 1 \mathrm{NaCl}, 0.3 \mathrm{~g} / 1$ $\mathrm{KCl}$ and $0.33 \mathrm{~g} / 1 \mathrm{CaCl}_{2} \cdot 2 \mathrm{H}_{2} \mathrm{O}$. The corrosion fatigue tests apparatus is shown in Fig. 3. The temperature of Ringer's solution was kept by thermostat, and circulated by a metering pump.

The specimen was etched by the solution of $2 \% \mathrm{HF}, 3 \%$ $\mathrm{HNO}_{3}$ and $95 \%$ pure water for microstructure observation. The microstructure was also observed using electron backscatter diffraction (EBSD). The hand-polished specimen

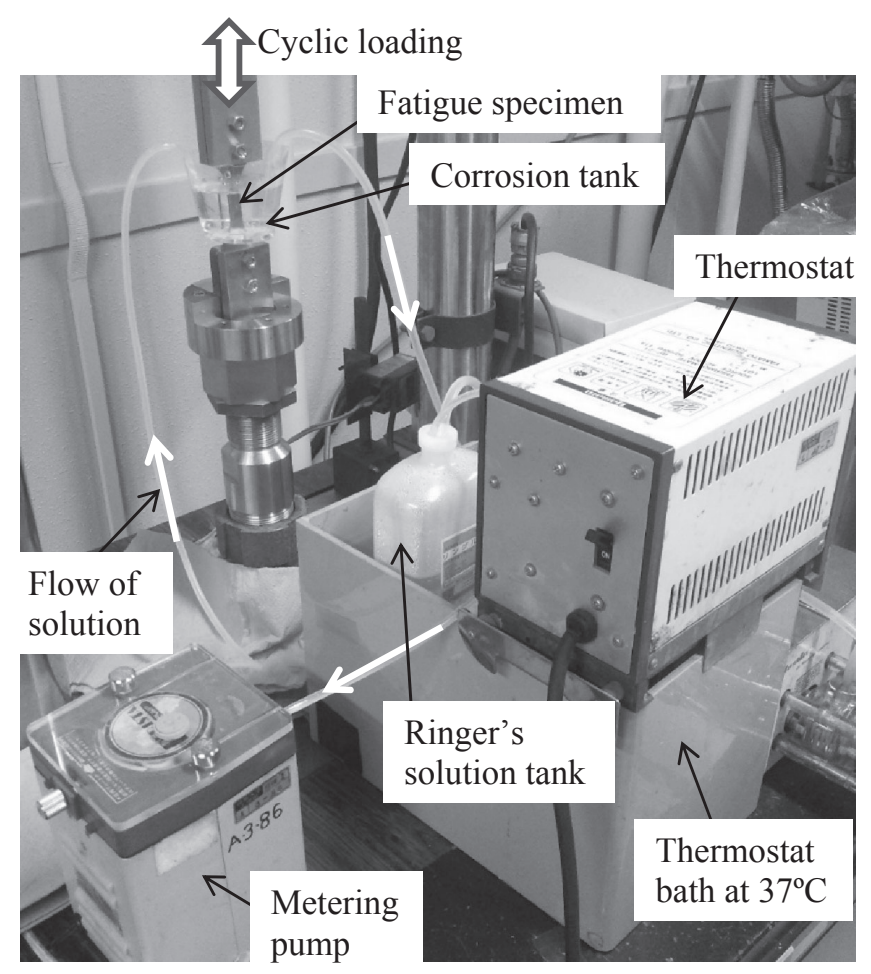

Fig. 3 Corrosion fatigue test apparatus.

was ion milled using HITACHI IM-3000 before EBSD analysis. X-ray diffraction (XRD) analysis was performed to observe the texture of the microstructure using RIGAKU SmartLab. Vickers hardness was measured by a micro Vickers hardness tester at the load of $2.94 \mathrm{~N}$ (300 gf) with the holding time of $30 \mathrm{~s}$.

\section{Results and Discussion}

\subsection{Microstructures and mechanical properties}

Figure 4 shows the microstructure of the reference material, TP35C, observed on the cross section of the plate (ND-TD plane). The grains are severely deformed by the cold rolling process, while some coarse grains are seen as indicated by the arrows in the figure. EBSD analysis was performed on the surface of the plate (RD-TD plane) as

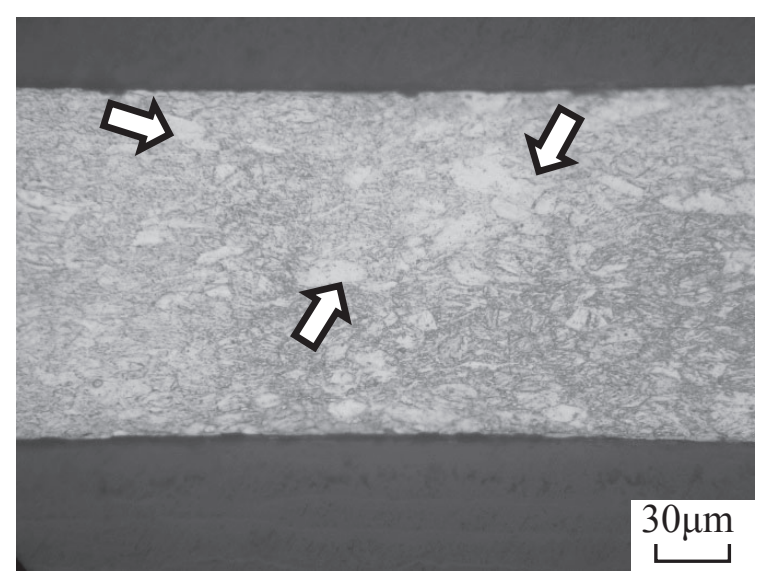

Fig. 4 Microstructure of TP35C observed on the cross section. Arrows indicate coarse grains. 

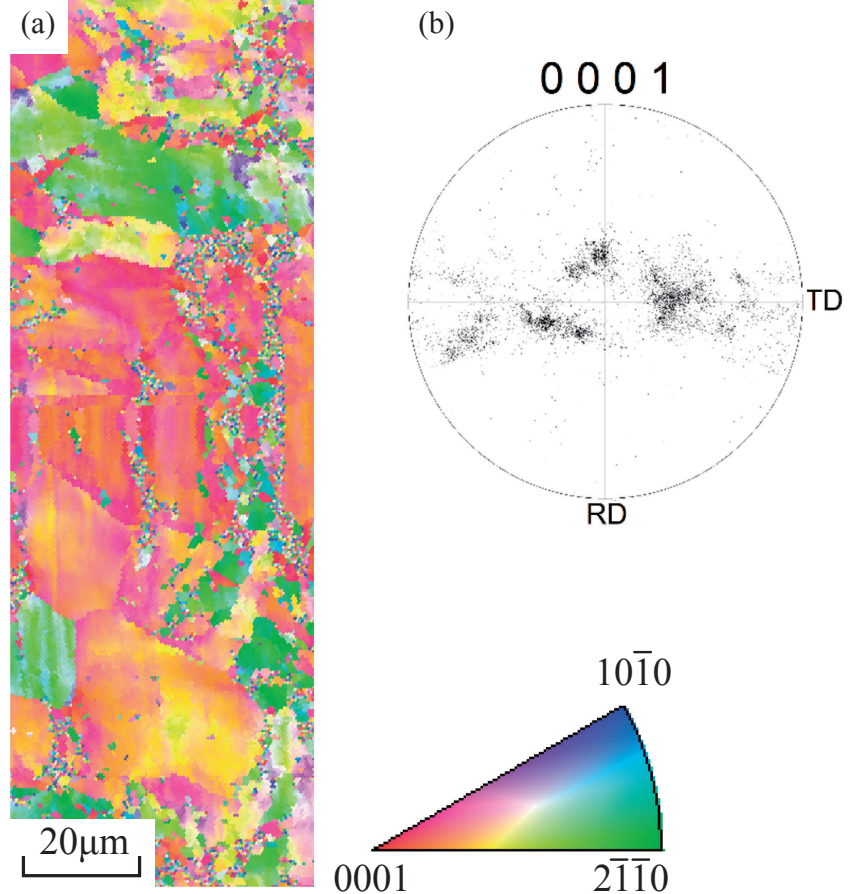

Fig. 5 EBSD analysis results of TP35C on RD-TD plane: (a) IPF map, (b) Pole figure of (0001) plane.

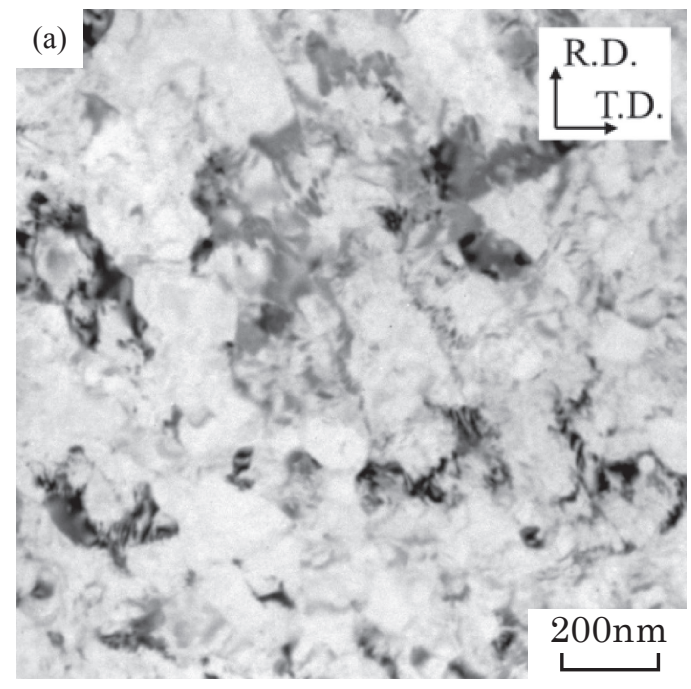

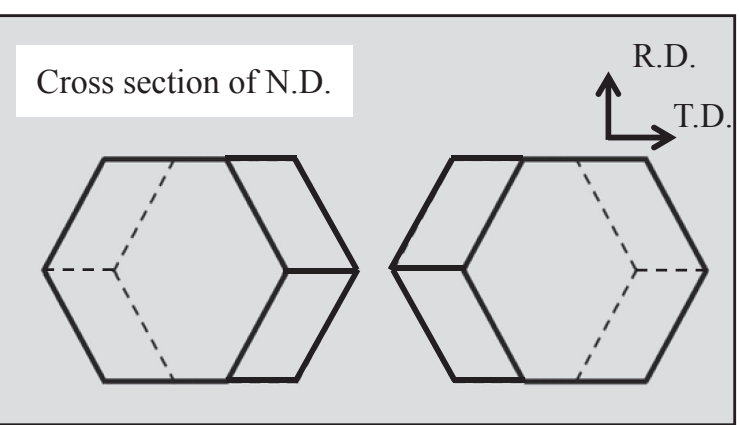

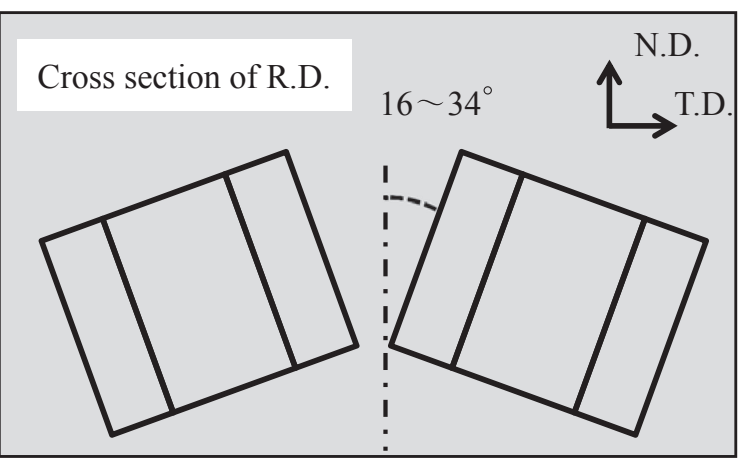

Fig. 7 Schematic illustration of texture in the MDFed Ti and TP35C plates.

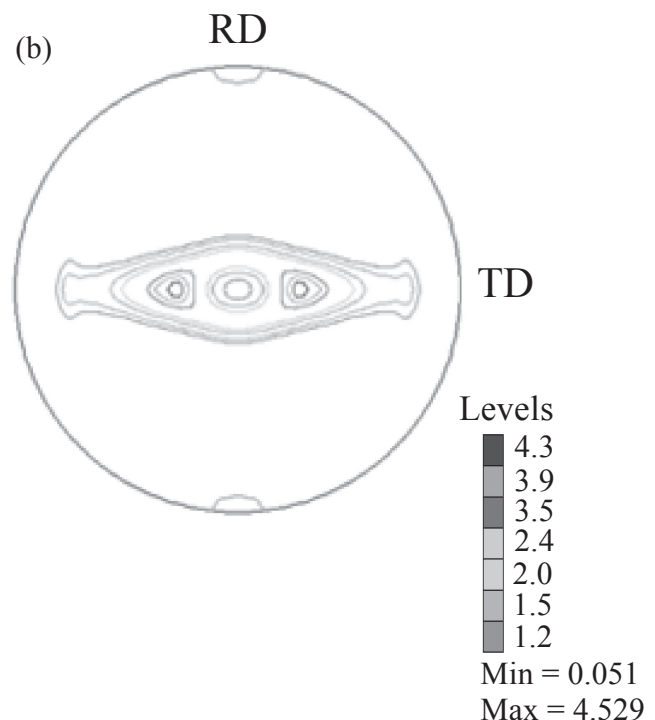

Fig. 6 Microstructure of MDFed Ti: (a) TEM image, (b) Pole figure of basal plane (0001) by XRD

shown in Fig. 5(a). It can be seen that the microstructure consists of some fine and coarse grains, in which the size of coarse grains was about $30 \mu \mathrm{m}$. Figure $5(\mathrm{~b})$ is the pole figure of (0001) plane. It reveals that the typical texture is formed by the cold rolling procedure. The TEM observation of MDFed Ti is shown in Fig. 6(a). The SPD by MDFing had resulted in very fine and homogeneous microstructure with an average grain size of $200 \mathrm{~nm}$. Although EBSD was performed on the surface of the MDFed $\mathrm{Ti}$ plate, clear Kikuchi bands could not be detected due to the large residual strain induced by MDFing. Therefore, XRD analysis was performed on the surface of the MDFed Ti plate. Figure 6(b) reveals the pole figure of (0001) plane, where the texture was confirmed to be similar to that of TP35C (Fig. 5(b)), where two [0001] axes symmetrically inclined about 16 to 34 degrees from ND axis. It is interesting to know, therefore, that a same texture develops irrespective of grain size. The texture developed in both plates is schematically drawn in Fig. 7. Dyakonov et al. reported similar texture in the heavily cold-rolled pure $\mathrm{Ti}$, in which the rolling reduction was $95 \% .^{22)}$

The mechanical properties of the MDFed Ti and TP35C plates are summarized in Table 1. MDFed Ti has higher properties than $\mathrm{TP} 35 \mathrm{C}$ due to much finer grains. In general, the material with higher tensile strength and proof stress has lower ductility. However, it should be emphasized that MDFed $\mathrm{Ti}$ has larger elongation than TP35C in spite of higher tensile strength. 
Table 1 Mechanical properties of material.

\begin{tabular}{ccccc}
\hline & Tensile & $0.2 \%$ proof & Elongation & Vickers \\
Materials & $\begin{array}{c}\text { strength } \\
\sigma_{\mathrm{B}}\end{array}$ & $\begin{array}{c}\sigma_{0.2} \\
(\mathrm{MPa})\end{array}$ & $\begin{array}{c}\delta \\
(\mathrm{MPa})\end{array}$ & $\begin{array}{c}\text { hardness } \\
H V\end{array}$ \\
\hline MDFed Ti & 920 & 766 & 18 & 459 \\
\hline TP35C & 746 & 619 & 7 & 258 \\
\hline
\end{tabular}

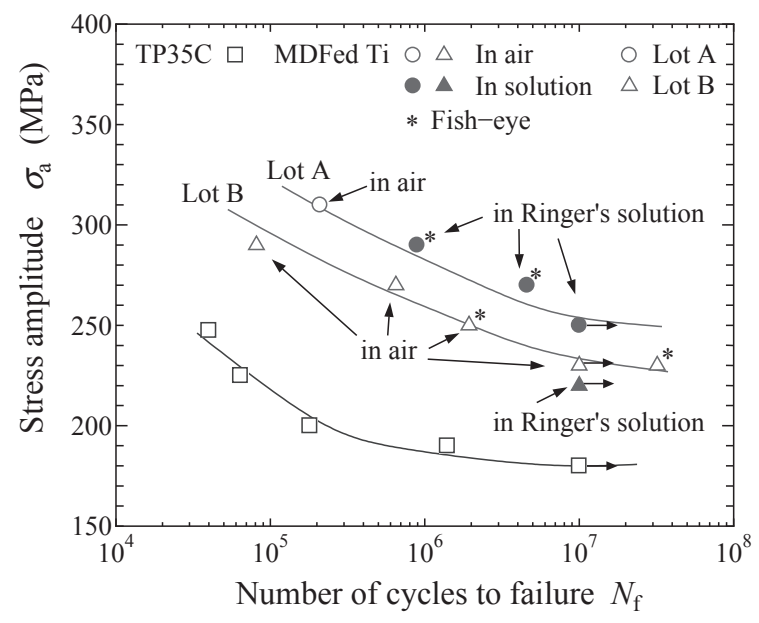

Fig. $8 S-N$ diagram.

\subsection{Fatigue strengths}

Figure 8 indicates the relationship between applied stress amplitude, $\sigma_{\mathrm{a}}$, and number of cycles to failure, $N_{\mathrm{f}}$, namely $S-N$ curves. Fatigue test results of MDFed Ti in air and in Ringer's solution are shown by open and solid symbols, respectively. The asterisk marks "*" in the figure will be mentioned in the next section. The large scatter is seen in the fatigue strengths of the MDFed Ti plates. But it could be attributed to the different lots from which fatigue specimens were prepared. In the present case, two lots A and B are used. It should be noted that fatigue strengths could be approximated by the $S-N$ curves for each lot. In general, MDFed materials have stable strength due to the repeated sever plastic deformation, ${ }^{14)}$ thus the different strengths between two lots might be attributed to the final rolling process.

Based on Fig. 8, there are two points which should be emphasized in the fatigue strengths. The first one is that the fatigue strengths of the MDFed Ti plates are superior to those of TP35C plates similar to their tensile strengths. The higher fatigue strengths of MDFed Ti could be attributed to the ultrafine grains induced by MDFing. In the present case, the thickness of the plates is 0.15 and $1 \mathrm{~mm}$ for TP35C and MDFed Ti plates, respectively. But the point is that TP35C is deeply-cold-rolled (highly-work-hardened) plate into the thickness of $0.15 \mathrm{~mm}$. It means that the MDFed Ti plate has higher fatigue strengths than the deeply-cold-rolled TP35C plate. Furthermore, both plates with the thickness of 0.15 and $1 \mathrm{~mm}$ are under the same stress state, namely under plane stress condition. Thus, the thickness itself has little effect on the fatigue strengths. The authors conducted fatigue tests of MDFed Ti thin films with the thickness of 15, 20, 30 and $50 \mu \mathrm{m}$, and proved that the fatigue strengths of the plate and films were nearly comparable. ${ }^{23)}$

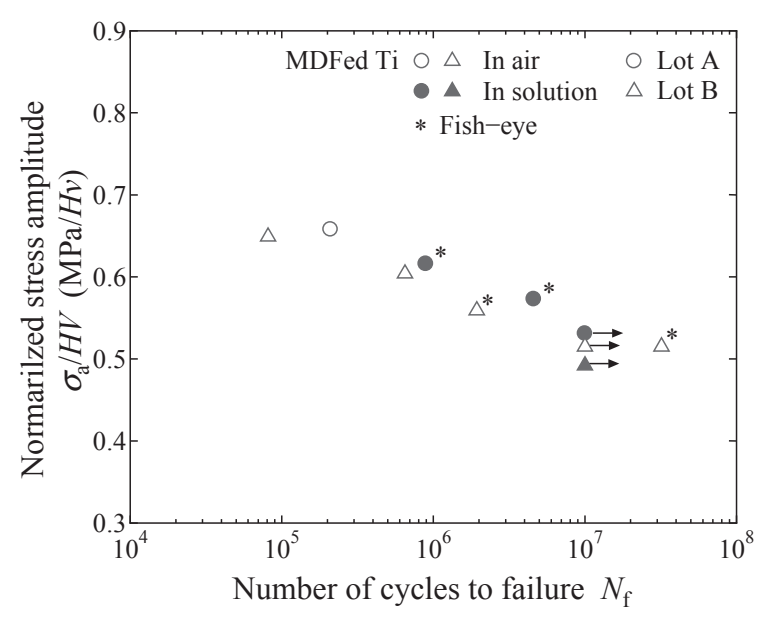

Fig. $9 S-N$ diagram normalized by Vickers hardness.

The second emphasizing point is the fatigue strengths of MDFed Ti in Ringer's solution shown by solid symbols. In the lots A and B, fatigue tests were conducted in air and in Ringer's solution using the specimens sampled from the same lots. But the $S-N$ curves in Ringer's solution and in air are the same. It indicates that degradation of fatigue strengths did not occur in Ringer's solution, and it proves the long-term durability of the MDFed Ti plates in human body. To verify the difference of the fatigue strengths between the lots A and B, Vickers hardness of both lots was measured separately. The average hardness of 20 measuring points was $471 H V$ and $447 \mathrm{HV}$ for the lots $\mathrm{A}$ and $\mathrm{B}$, respectively. Figure 9 indicates the $S-N$ diagram in terms of the normalized applied stress amplitude by Vickers hardness. The difference of fatigue strengths between two lots became smaller, indicating that the scatter shown in Fig. 8 could be attributed to the different hardness.

\subsection{Fractographic analyses}

Figure 10 shows the typical fatigue fracture surface and magnified view at the crack initiation site of TP35C. Fatigue crack initiated at the corner of the plate, and flat feature at the crack initiation site indicates that cyclic slip deformation resulted in the crack initiation. This surface fatigue crack initiation and propagation mechanisms are typical in many metals. As shown in Fig. 10, the specimen surface near the corner edges are slightly curved by the polishing process of the surface before fatigue test. But as shown by the scale bar in Fig. 10(a), the change of the cross sectional shape is quite small, because the width of the specimen is $14.9 \mathrm{~mm}$. Thus, it is reasonable to consider that the macroscopic cross sectional shape is rectangular.

Figure 11 shows the fatigue fracture surfaces of MDFed $\mathrm{Ti}$, where the crack initiation site is indicated by the arrow in the figure. The fatigue crack initiated on the surface of MDFed Ti similar to TP35C. However, sub-surface crack initiation with fish eye was sometimes recognized in MDFed $\mathrm{Ti}$ as shown in Fig. 12. In general, sub-surface crack initiation is typically seen in HCF fracture of high strength steels $^{24,25)}$ or surface treated alloys, such as DLC-coated magnesium alloy ${ }^{26)}$ or ultrasonic shot-peened $\beta$-type $\mathrm{Ti}$ alloy. ${ }^{27)}$ But sub-surface crack initiation was hardly reported 

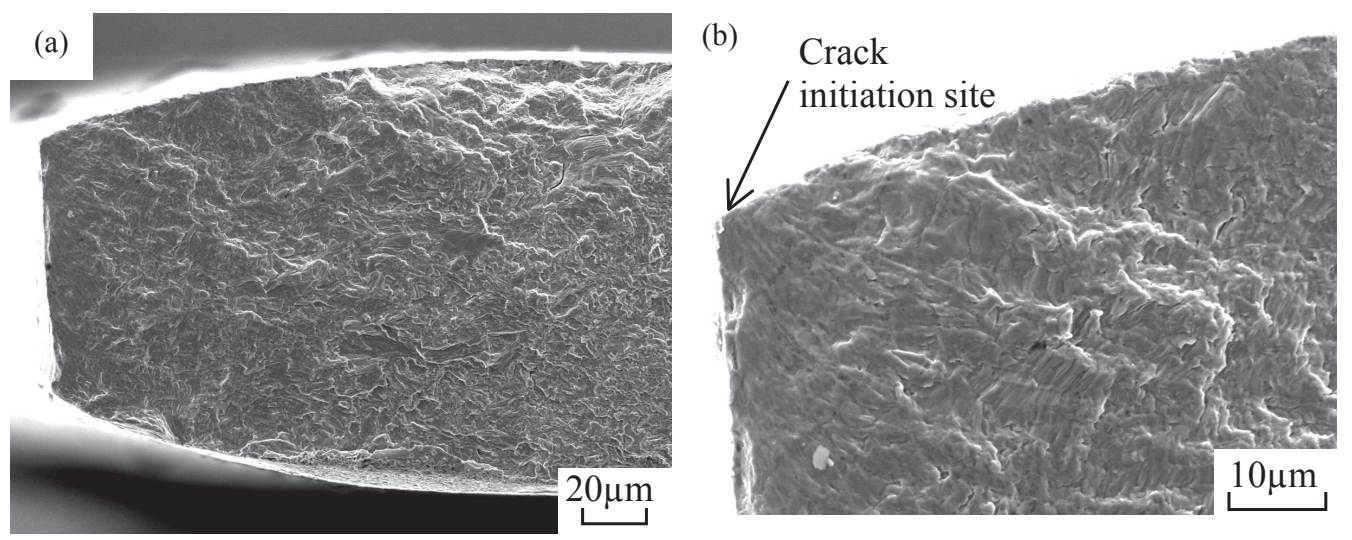

Fig. 10 Fatigue fracture surfaces of TP35C: (a) Overview, (b) Magnified view at the crack initiation site $\left(\sigma_{\mathrm{a}}=190 \mathrm{MPa}, N_{\mathrm{f}}=1.4 \times 10^{6}\right)$.

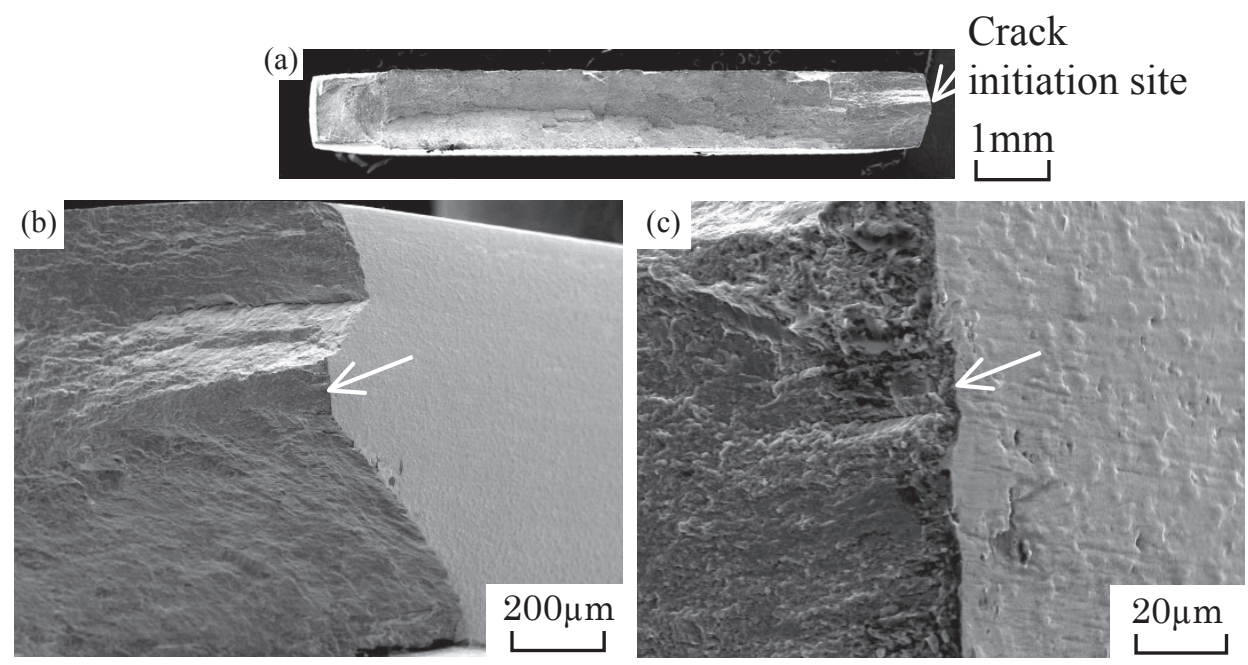

Fig. 11 Fatigue fracture surfaces of MDFed Ti in laboratory air (Surface crack initiation): (a) Overview, (b) and (c) Magnified views at the crack initiation site $\left(\sigma_{\mathrm{a}}=270 \mathrm{MPa}, N_{\mathrm{f}}=6.5 \times 10^{5}\right.$, Lot B).
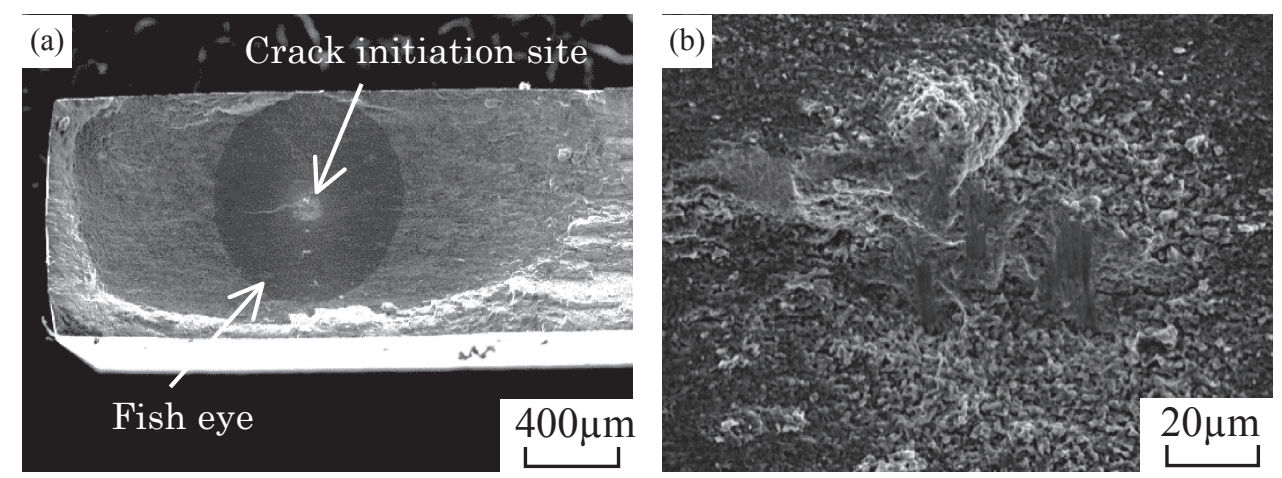

Fig. 12 Fatigue fracture surfaces of MDFed Ti in laboratory air (Sub-surface crack initiation): (a) Overview, (b) Magnified views at the crack initiation site $\left(\sigma_{\mathrm{a}}=230 \mathrm{MPa}, N_{\mathrm{f}}=3.2 \times 10^{7}\right.$, Lot B).

in pure Ti, thus it means that the present case is quite unique phenomena for MDFed Ti.

In Figs. 8 and 9, sub-surface crack initiation was denoted by the asterisk marks “*”. It should be noted that sub-surface crack initiation occurred in the HCF regime, where the number of cycles to failure was longer than $10^{6}$ cycles. At the stress amplitude, $\sigma_{\mathrm{a}}$, of $240 \mathrm{MPa}$, the fatigue test run out at $10^{7}$ cycles in air, which could be defined as fatigue limit. The fatigue test at $240 \mathrm{MPa}$ was then continued until final fracture. Consequently, fatigue fracture occurred at $3.20 \times$ $10^{7}$ cycles (very high cycle fatigue (VHCF) regime) with sub-surface crack initiation with fish eye (Fig. 12). It indicates that sub-surface fatigue crack initiation occurs in HCF and VHCF regimes. The other emphasis is that subsurface crack initiation occurred even in Ringer's solution. Figure 13 shows the sub-surface crack initiation in Ringer's solution. If the corrosive environment degrades fatigue properties, surface crack initiation must dominate fatigue 

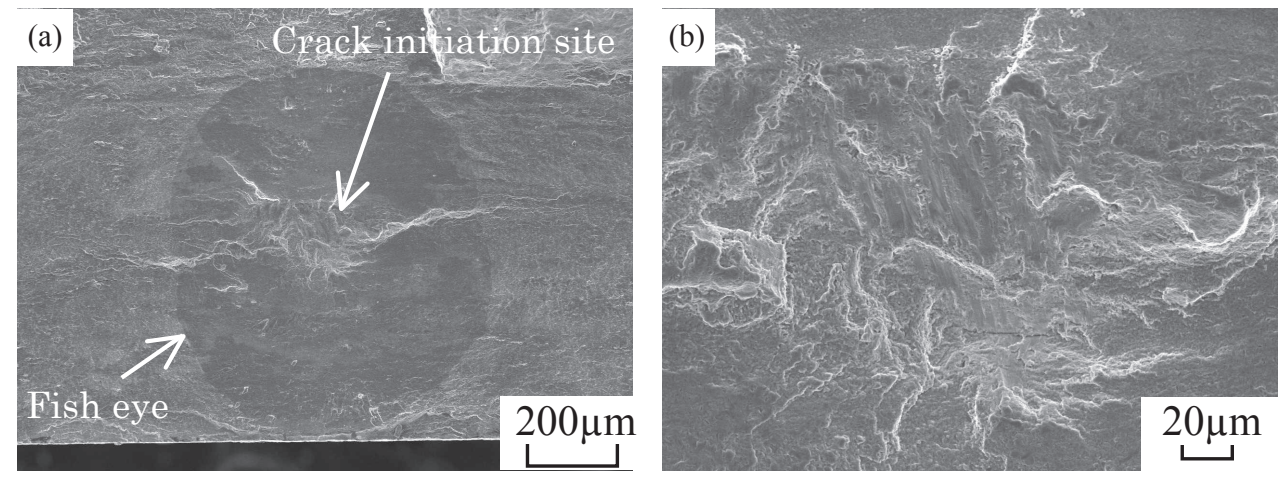

Fig. 13 Fatigue fracture surfaces of MDFed Ti in Ringer's solution air (Sub-surface crack initiation): (a) Overview, (b) Magnified views at the crack initiation site $\left(\sigma_{\mathrm{a}}=230 \mathrm{MPa}, N_{\mathrm{f}}=8.9 \times 10^{6}\right.$, Lot A).

fracture in HCF regime because corrosion occurs on the specimen surface. Therefore, sub-surface crack initiation in Ringer's solution also proves the high corrosion fatigue resistance of MDFed $\mathrm{Ti}$.

\subsection{Sub-surface crack initiation analyses}

In Ti-6Al-4V alloy, sub-surface crack initiation had been reported in HCF regime. ${ }^{28-30)}$ Oguma et al. concluded that sub-surface crack initiation occurred due to the cleavage fracture of $\alpha$-phase in $\alpha+\beta$ microstructure. ${ }^{28)}$ Therefore, sub-surface crack initiation could be attributed to the inhomogeneous $\alpha+\beta$ microstructure of Ti-6Al-V alloy. However, the microstructure of MDFed Ti consists only of homogeneous $\alpha$-phase. The sub-surface crack initiation has not been reported for pure Ti. Thus, the sub-surface crack initiation mechanism in MDFed $\mathrm{Ti}$ is investigated in detail as follows.

In the high strength steels, inclusions such as intermetallic compound (IMC) and oxide with the size of dozens $\mu \mathrm{m}$ are generally recognized at the sub-surface crack initiation sites. ${ }^{24,25)}$ It indicates that inclusions dominate sub-surface crack initiation mechanism. Thus, the sub-surface crack initiation site, namely the center of the fish-eye was analyzed by EDS to identify IMC. Figure 14 indicates the magnified view at the sub-surface crack initiation site and Ti mapping. Figure 14(a) is the matching fracture surface of Fig. 12(b), namely the other side of the fracture surface. The spectrum of EDS is also shown in the figure. Only Ti was detected at the center of fish eye, indicating that the sub-surface crack initiation could not be related to inclusions, but to the other microstructural factor.

Subsequently EBSD analysis was conducted near the center of fish eye of Fig. 14(a). It is impossible to apply EBSD analysis directly on the rough fatigue fracture surface. Thus, the fracture surface was polished by emery paper with the depth about $20 \mu \mathrm{m}$ and then ion milled to get mirror surface. Subsequently, EBSD was performed and the SEM image and invers pole figure are shown in Fig. 15. The EBSD analysis was conducted in the rectangular area in Fig. 15(a). The area, where Confidence Index (CI) value was lower than 0.1, is shown in black in Fig. 15(b). The MDFed Ti was severely deformed, thus most area is covered by black with low CI values. However, it should be noted that some grains with the size larger than $1 \mu \mathrm{m}$ are detected. The
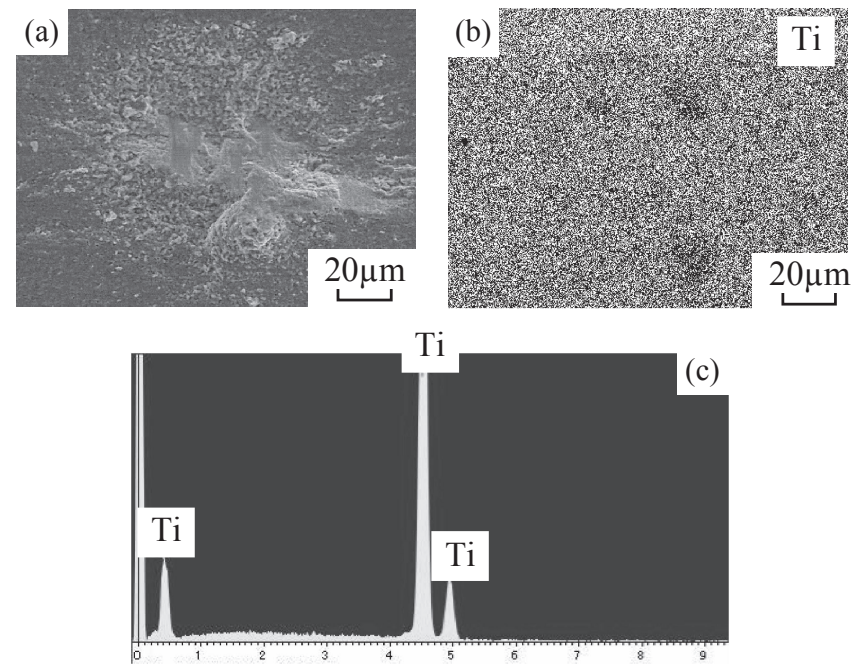

Fig. 14 EDS analysis result: (a) SEM image of sub-surface crack initiation site, (b) Ti mapping, (c) EDS spectrum $\left(\sigma_{\mathrm{a}}=230 \mathrm{MPa}, N_{\mathrm{f}}=3.2 \times 10^{7}\right.$, Lot B).
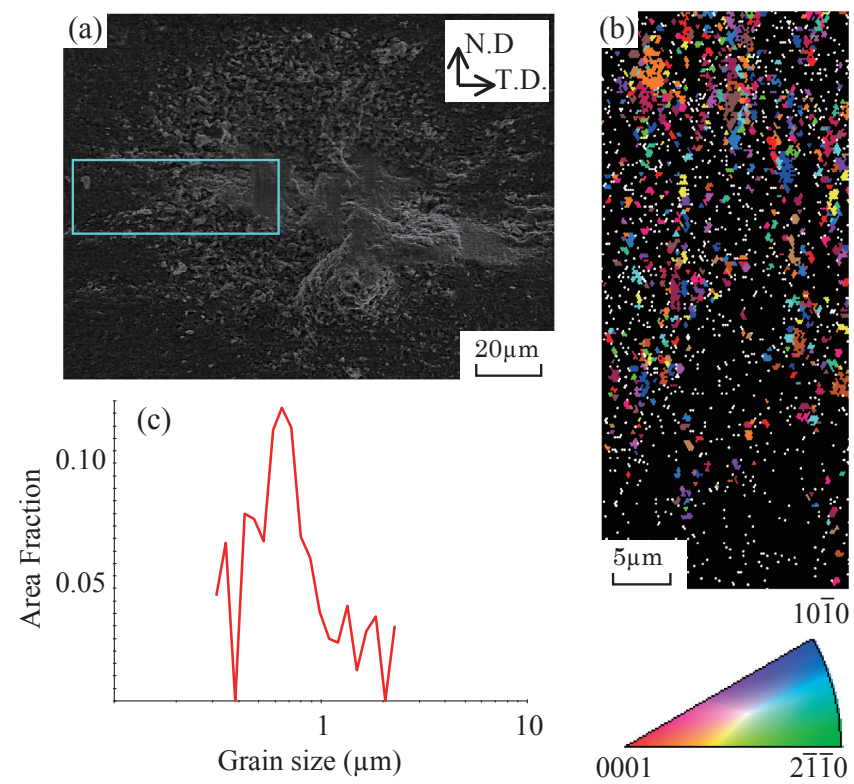

Fig. 15 EBSD analysis result: (a) SEM image of sub-surface crack initiation site, (b) Pole figure of the rectangular area in Fig. (a), (c) Distribution of grain sizes $\left(\sigma_{\mathrm{a}}=230 \mathrm{MPa}, N_{\mathrm{f}}=3.2 \times 10^{7}\right.$, Lot B). 
(a)

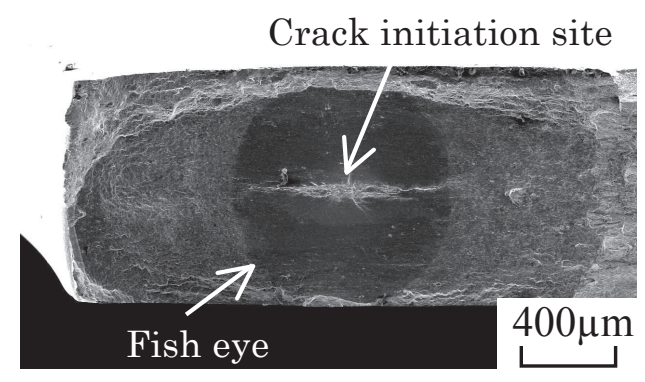

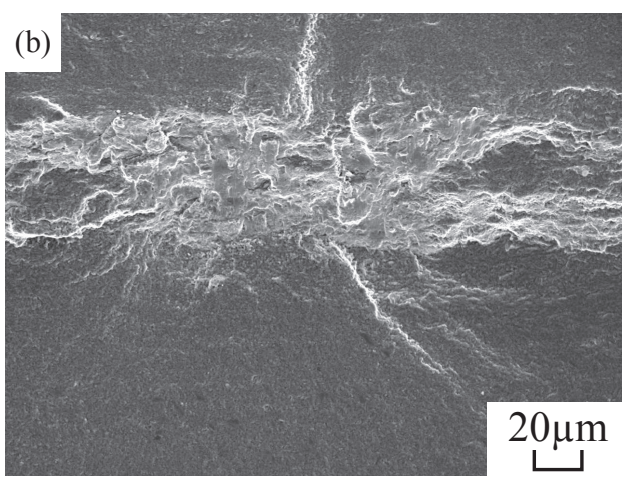

Fig. 16 Fatigue fracture surfaces of MDFed Ti in laboratory air (Sub-surface crack initiation): (a) Overview, (b) Magnified views at the crack initiation site $\left(\sigma_{\mathrm{a}}=250 \mathrm{MPa}, N_{\mathrm{f}}=1.9 \times 10^{6}\right.$, Lot B).

average grain size obtained from TEM observation was $200 \mathrm{~nm}$ as shown in Fig. 6. Figure 15 indicates that grain size inhomogeneity exist in the material. The grain size distribution is also shown in Fig. 15(c) in terms of area fraction. When EBSD analyses were conducted on the specimen surface, clear Kikuchi bands were not obtained at all, thus the analytical result was shown only by black area with low CI values. However, some coarser grains are detected near the mid thickness of the MDFed Ti plates as shown in Fig. 15. The other fish-eye fracture surface is shown in Fig. 16. As shown in Figs. 12(a), 13(a) and 16(a), sub-surface cracks predominantly initiated near the mid thickness of the plates. It is considered that sub-surface cracks initiated at coarse grains near the mid thickness. Consequently, it could be concluded that the inhomogeneity of grain sizes near the mid thickness of the plates resulted in the sub-surface crack initiation. As mentioned above, clear Kikuchi bands were not obtained on the specimen surface. Therefore, it is considered that the microstructure is homogeneous on the specimen surface, but inhomogeneity exits near the mid thickness.

It is summarized that the mechanical and fatigue properties of the MDFed Ti plates were superior to those of TP35C plates due to much finer grains. Oguma et al. conducted fatigue tests using $\mathrm{Ti}-6 \mathrm{Al}-4 \mathrm{~V}$ at the stress ratio, $R=0.1$, which was the same with the present case. ${ }^{28)}$ They concluded that the fatigue limit stress amplitude was 225-248 MPa. In the present paper, the fatigue limits are 250 and $220 \mathrm{MPa}$ for the lots A and B, respectively. It could be concluded that combined process of MDFing and rolling of commercial purity grade $2 \mathrm{Ti}$ derives drastic improvement of fatigue strengths comparable to Ti-6Al-4V. Furthermore, no degradation of fatigue properties occurred in Ringer's solution, indicating good applicability of the MDFed $\mathrm{Ti}$ plates as medical implants. Unique sub-surface crack initiation was recognized in the HCF and VHCF regimes of the MDFed Ti plates, which could be attributed to the grain size inhomogeneity.

\section{Conclusions}

Tension-tension fatigue tests were conducted using commercial purity grade $2 \mathrm{Ti}$ thin plates with the thickness of $1 \mathrm{~mm}$ fabricated by a combined process of multi- directional forging (MDFing) and rolling (simply referred as MDFing) in air and in Ringer's solution. Cold-rolled conventional commercial purity grade $2 \mathrm{Ti}$, TP35C, plate was used as reference material. Based on the experimental results, the following conclusions can be made:

1. Microstructural observation revealed that the average grain size of the MDFed Ti plate was $200 \mathrm{~nm}$, while the microstructure of $\mathrm{TP} 35 \mathrm{C}$ was a mixture of fine and coarse grain colonies. The size of the coarse grain was about $30 \mu \mathrm{m}$. EBSD and XRD analyses revealed that similar textures were formed in both plates.

2. The MDFed Ti plate exhibited higher tensile properties than the TP35C plate. The elongation of the MDFed $\mathrm{Ti}$ plate was also larger than that of TP35C. The enhancement of tensile properties of MDFed Ti without any reduction of ductility could be attributed to the ultrafine grains achieved by MDFing.

3. Fatigue strengths of the MDFed Ti plates were higher than those of the TP35C plates due to the ultrafinegrained microstructure. Degradation of fatigue properties of MDFed Ti did not occur in Ringer's solution.

4. Sub-surface crack initiation of the MDFed Ti plates was observed in the high cycle fatigue regime, where number of cycles to failure was longer than $10^{6}$ cycles. Microstructural observation proved that inclusions were not at the sub-surface crack initiation site. Based on the EBSD analysis, it was found that some coarse grains with the size of a few $\mu \mathrm{m}$ existed inner part of the MDFed Ti plate. The sub-surface crack initiation could be attributed to the grain size inhomogeneity.

\section{Acknowledgement}

Main author's gratitude also appointed to Indonesia Dikti scholarship for financial support on the $\mathrm{PhD}$ program at Gifu University. All the experiments were done in Japan.

\section{REFERENCES}

1) M. Niinomi: Mater. Sci. Eng. A 243 (1998) 231-236.

2) T. Akahori and M. Niinomi: Mater. Sci. Eng. A 243 (1998) 237-243.

3) C. Fleck and D. Eifler: Int. J. Fat. 32 (2010) 929-935.

4) R.B. Osman and M.V. Swain: Materials (Basel) 8 (2015) 932-958.

5) C.C. Gomes, L.M. Moreira, V.J.S.V. Santos, A.S. Ramos, J.P. Lyon, C.P. Soares and F.V. Santos: Genet. Mol. Biol. 34 (2011) 116-121. 
6) R.Z. Valiev, Y. Estrin, Z. Horita, T.G. Langdon, M.J. Zehetbauer and Y.T. Zhu: Mater. Res. Lett. 4 (2016) 1-21.

7) R.B. Figueiredo, E.R.C. Barbosa, X. Zhao, X. Yang, X. Liu, P.R. Cetlin and T.G. Langdon: Mater. Sci. Eng. A 619 (2014) 312-318.

8) G.S. Dyakonov, E. Zemtsova, S. Mironov, I.P. Semenova, R.Z. Valiev and S.L. Semiatin: Mater. Sci. Eng. A 648 (2015) 305-310.

9) Y. Kaneko, S. Hayashi and A. Vinogradov: Mater. Trans. 54 (2013) 1612-1618.

10) E. Bruder, C. Gangaraju and R. Lapovok: Mater. Sci. Eng. A 711 (2018) 650-658.

11) O.F. Higuera-Cobos, J.A. Berríos-Ortiz and J.M. Cabrera: Mater. Sci. Eng. A 609 (2014) 273-282.

12) Y. Harai, M. Kai, K. Kaneko, Z. Horita and T.G. Langdon: Mater. Trans. 49 (2008) 76-83.

13) Y.S. Sato, Y. Kurihara, S.H.C. Park, H. Kokawa and N. Tsuji: Scr. Mater. 50 (2004) 57-60.

14) H. Miura, X. Yang and T. Sakai: Mater. Trans. 49 (2008) 1015-1020.

15) H. Miura, T. Maruoka and J.J. Jonas: Mater. Sci. Eng. A 563 (2013) 53-59.

16) B. Wang, X. Wang and J. Li: J. Mater. Eng. Perform. 25 (2016) 25212527.

17) Y. Uematsu, T. Kakiuchi, H. Miura and T. Nozaki: Mater. Trans. 57 (2016) 1454-1461.

18) T. Aoba, M. Kobayashi and H. Miura: Mater. Sci. Eng. A 700 (2017) $220-225$.
19) H. Miura and M. Kobayashi: Titanium Japan 64 (2014) 191-193 (in Japanese).

20) N. Hoshi, M. Saita, T. Kumasaka, M. Banka, H. Miura and K. Kimoto: J. Jpn. Soc. Dental Mater. Devices 32 (2013) 403 (in Japanese).

21) Tonichi Shimbun News: http://data.zenkokunews.com/201405/26/ 2014-05-26-tonichi.pdf, (accessed 2018-04-26) (in Japanese).

22) G.S. Dyakonov, S. Mironov, S.V. Zherebtsov, S.P. Malysheva, G.A. Salishchev, A.A. Salem and S.L. Semiatin: Mater. Sci. Eng. A 607 (2014) 145-154.

23) Ilhamdi, Y. Uematsu, H. Miura, T. Kakiuchi, T. Shimizu, Y. Nakamura and M. Nakajima: Proceedings of JSME annual meeting, (The Japan Society of Mechanical Engineers, 2017) No. 17-1 (CD-ROM) (in Japanese).

24) T. Abe, Y. Furuya and S. Matsuoka: Fatigue Fract. Eng. Mater. Struct. 27 (2004) 159-167.

25) A. Roiko and Y. Murakami: Int. J. Fat. 41 (2012) 140-149.

26) Y. Uematsu, K. Tokaji and H. Takekawa: Fatigue Fract. Eng. Mater. Struct. 33 (2010) 607-616.

27) Y. Uematsu, T. Kakiuchi and K. Hattori: Fatigue Fract. Eng. Mater. Struct., in press, https://doi.org/10.1111/ffe.12812.

28) H. Oguma, T. Nakamura, S. Yokoyama and T. Noguchi: J. Soc. Mat. Sci., Japan 52 (2003) 1298-1304 (in Japanese).

29) X. Liu, C. Sun and Y. Hong: Mater. Sci. Eng. A 622 (2015) 228-235.

30) S. Heinz and D. Eifler: Int. J. Fat. 93 (2016) 301-308. 